\title{
Coexistence Of Two Kinds of Fluorinated-Hydrogenated Micelles As Building Blocks For the Design of Bimodal Mesoporous Silica With Two Ordered Mesopore Networks
}

\begin{tabular}{|c|c|}
\hline Journal: & Langmuir \\
\hline Manuscript ID: & la-2011-03753q.R2 \\
\hline Manuscript Type: & Letter \\
\hline $\begin{array}{r}\text { Date Submitted by the } \\
\text { Author: }\end{array}$ & 28-Oct-2011 \\
\hline Complete List of Authors: & $\begin{array}{l}\text { May, Anna; Barcelona University, Chemical Engineering } \\
\text { Stebe, Marie Jose; University of Henri Poincaré Nancy 1, UMR } 7565 \\
\text { Gutierrez, Jose; Universidad de Barcelona, Ingenieria Quimica } \\
\text { Blin, Jean-Luc; University of Nancy-1, Equipe Physicochimie des } \\
\text { Collö̈des }\end{array}$ \\
\hline
\end{tabular}

\section{SCHOLARONE Manuscripts}




\title{
Coexistence Of Two Kinds of Fluorinated-Hydrogenated Micelles As Building Blocks For the Design of Bimodal Mesoporous Silica With Two Ordered Mesopore Networks
}

\author{
A. May ${ }^{a}$, M.J. Stébéb ${ }^{\text {, J.M. Gutiérrez }}{ }^{\mathrm{a}}$ and J.L. Blin ${ }^{\mathrm{b}}$ \\ ${ }^{a}$ : Chemical Engineering Department, Chemistry Faculty, Universitat de Barcelona, Martí i \\ Franquès 1-11, 08028, Barcelona, Catalonia, Spain \\ ${ }^{\mathrm{b}}$ : Equipe Physico-chimie des Colloïdes, UMR SRSMC N 7565 Université Henri Poincaré - \\ Nancy 1 / CNRS, Faculté des Sciences, BP 239, F-54506 Vandoeuvre-les-Nancy cedex, \\ France
}

\begin{abstract}
A simple and effective route has been developed for the synthesis of bimodal (3.6 and $9.4 \mathrm{~nm}$ ) mesoporous silica materials that have two ordered interconnected pore networks. Mesostructures have been prepared through the self assembly mechanism by using a mixture of polyoxyethylene fluoroalkyl ether and triblock copolymer as building block. The investigation of the $\mathrm{R}_{8}^{\mathrm{F}}(\mathrm{EO})_{9} / \mathrm{P} 123 /$ water phase diagram evidences that in the considered surfactant range of concentrations, the system is micellar $\left(\mathrm{L}_{1}\right)$. DLS measurements indicate that this micellar phase is composed of two types of micelles, the size of the first one at around $7.6 \mathrm{~nm}$ corresponds unambiguously to the pure fluorinated micelles. The second type of micelles at higher diameter consists of fluorinated micelles which have accommodated a weak fraction of P123 molecules. Thus, in this study the bimodal mesoporous silica are really templated by two kinds of micelles.
\end{abstract}




\section{Introduction}

Porous materials have found wide applications in many fields of chemistry such as catalysis, adsorption, electronics and environmental technology because of their high surface area coupled with many other physical and chemical properties ${ }^{1-5}$. Recently, there has been a rapid growth in emerging research areas such as nanotechnology, photonics and bioengineering, which require porous structures with well-defined structural, interfacial, compositional and morphological properties. However, these applications often require materials with porosity at multiple length scales. For example, it was reported that a hierarchical combination of pores reduces transport limitations in catalysis, resulting in higher activities and better controlled over selectivity ${ }^{6}$. The development of hierarchical porous materials has therefore attracted much interest over the past few years and in the literature many papers are focused on the synthesis of meso-macro, micro-macro or micro-mesoporous materials ${ }^{7-14}$. However, only few of them deal with bimodal systems having two types of mesopores ${ }^{15-20}$. In addition, the recovered materials either adopt disordered bimodal mesopore arrangements or ordered mono-modal mesopore with small size template molecular systems embedded in larger entities. One strategy to prepare these bimodal mesoporous materials consists in using mixtures of templates ${ }^{18,19,21-24}$. For example Morris et al. employed mixtures of micellar solutions of nonionic surfactants, including Pluronic, Brij and Tetronic types, as templates for synthesizing porous silica materials having mixed pore sized ${ }^{21}$. Depending on the surfactant mixture, ordered uniform pore size arrangements, partially ordered complex bimodal structures or totally disordered non-mesoporous structures were obtained. Among the surfactant mixtures, the ones of fluorinated and hydrogenated surfactants are useful in specific practical applications, so these mixtures in aqueous systems have been widely investigated by different techniques such as light scattering, NMR and Small Angle Neutron Scattering ${ }^{25-28}$. It has been observed that, in these systems, either mixed micelles containing both surfactants in 
a well-defined proportion, or two kinds of micelles enriched in one of the two components can be formed. In fact, fluorinated surfactants have chemical and physical properties that are different from hydrogenated ones. Due to the difference in polarities between the fluorocarbon and hydrocarbon chains, nonideal net repulsive interactions can occur. Therefore, these surfactant mixtures appear to be excellent candidates to design bimodal mesostructures. Rankin et al. have adopted this methodology to synthesize bimodal mesoporous silica by the cooperative assembly of hydrolyzed tetraethoxysilane (TEOS) with a mixture of ionic fluorinated and hydrogenated surfactants ${ }^{19}$. Although the authors succeed in tailoring the bimodal pore size by adding lipophilic or fluorophilic oils, disordered wormholelike pores are formed. Antionetti et al. have also reported the synthesis, from mixed micellar solutions of nonmiscible fluorinated and hydrogenated surfactants, of mesoporous silica monoliths with bimodal pore size distribution via the nanocasting process ${ }^{18}$. Nevertheless, to the best of our knowledge no bimodal mesoporous materials with two ordered mesoporous networks have been yet synthesized. In this paper we report this kind of mesostructures. Our strategy is based on the use of a mixture of polyoxyethylene fluoroalkyl ether and triblock copolymer as building block to design the bimodal silica mesoporous through the self assembly mechanism (CTM).

\section{Materials and methods}

The used fluorinated surfactant, which was provided by DuPont, has an average chemical structure of $\mathrm{C}_{8} \mathrm{~F}_{17} \mathrm{C}_{2} \mathrm{H}_{4}\left(\mathrm{OC}_{2} \mathrm{H}_{4}\right)_{9} \mathrm{OH}$. It is labeled as $\mathrm{R}_{8}^{\mathrm{F}}(\mathrm{EO})_{9}$. The hydrophilic chain moiety exhibits a Gaussian chain length distribution and the hydrophobic part is composed of well defined mixture of fluorinated tails. The selected triblock copolymer is the Pluronic P123 $(\mathrm{EO})_{20}(\mathrm{PO})_{70}(\mathrm{EO})_{20}$, which was purchased from Aldrich. 
Mesoporous material preparation : In a typical synthesis, $0.9 \mathrm{~g}$ of $\mathrm{R}_{8}{ }_{8}(\mathrm{EO})_{9}$ and $0.1 \mathrm{~g}$ of $\mathrm{P} 123$ are dissolved in a hydrochloric acid solution $(\mathrm{pH}=0.3)$ to form a micellar solution containing 10 wt. $\%$ of surfactant. The weight fraction of P123 in the surfactant mixtures was varied from 0 to 0.2 . Then $0.32 \mathrm{~g}$ of tetramethoxysilane (TMOS), used as the silica source, is added dropwise into the micellar solution at $20^{\circ} \mathrm{C}$ and let under gentle stirring (150 rpm) for 1 hour. The obtained samples are sealed in Teflon autoclaves and heated at $80^{\circ} \mathrm{C}$ for 1 day. The final products are recovered after ethanol extraction with a Soxhlet apparatus during 48 hours. We have reported that under these synthesis conditions, a hexagonal pore ordering can be obtained from the self-assembly mechanism by using the fluorinated surfactant ${ }^{29,30}$. To free the pores either the calcination method, which can damage the materials, or the solvent extraction, can be employed. Nonionic surfactants appear to be excellent candidates for the second approach. Indeed, due the weaker interactions between the entities, the removal of these surfactants can easily be achieved by solvent extraction. In addition, the efficiency of the fluorinated surfactant removal has also been followed by infrared (see supporting information S1). No evidence of CF absorption is observed on the FTIR spectrum. The quantity of $\mathrm{R}_{8}{ }_{8}(\mathrm{EO})_{9}$, that remains after extraction is expected to be negligible.

Characterization : SAXS measurements were carried out using SAXSess mc2 (Anton Paar) apparatus. It is attached to a ID 3003 laboratory X-Ray generator (General Electric), equipped with a sealed X-ray tube (PANalytical, $\lambda_{\mathrm{Cu}(\mathrm{K} \alpha)}=0.1542 \mathrm{~nm}, \mathrm{P}=3.3 \mathrm{~kW}$ ). A multilayer mirror and a block collimator provide a monochromatic primary beam. A translucent beam stop allows the measurement of an attenuated primary beam at $q=0$. Samples are introduced into a powder cell and placed inside an evacuated chamber. Acquisition times are typically in the range of 1 to 5 minutes. Scattering of X-ray beam is recorded by a CCD detector (Princeton Instruments, $2084 \times 2084$ pixels array with $24 \times 24 \mu \mathrm{m}^{2}$ pixel size) in the q range 0.04 to $5 \mathrm{~nm}^{-1}$. The detector is placed at $309 \mathrm{~mm}$ from the sample holder. Samples for transmission 
electron microscopy (TEM) analysis were prepared by crushing some material in ethanol. Afterwards a drop of this slurry was dispersed on a holey carbon coated copper grid. A Philips CM20 microscope, operated at an accelerating voltage of $200 \mathrm{kV}$, was used to record the images. $\mathrm{N}_{2}$ adsorption and desorption isotherms were determined on a Micromeritics TRISTAR 3000 sorptometer at $-196{ }^{\circ} \mathrm{C}$. The pore diameter and the pore size distribution were determined by the BJH (Barret, Joyner, Halenda) ${ }^{31}$ method applied to the adsorption branch of the isotherm. Dynamic Light Scattering (DLS) experiments were performed with a Malvern 300HSA Zetasizer instrument.

\section{Results and discussion}

When mesoporous materials are prepared through the CTM mechanism, the surfactant has to form micelles in water; it is well known that both $\mathrm{R}_{8}^{\mathrm{F}}(\mathrm{EO})_{9}$ and $\mathrm{P} 123$ answer this criterion. In addition, the investigation of the $\mathrm{R}_{8}^{\mathrm{F}}(\mathrm{EO})_{9} / \mathrm{P} 123 /$ water phase diagram reveals that in the water rich part of the diagram, at least up to a total surfactant concentration equal to $15 \mathrm{wt} . \%$, a micellar solution is obtained whatever the ratio between $\mathrm{R}_{8}^{\mathrm{F}}(\mathrm{EO})_{9}$ and $\mathrm{P} 123$ (see supporting information S2). However, as our goal is to synthesize a material with a bimodal pore size distribution, the mixture of surfactants should lead to the formation of a micellar solution containing micelles of two different diameters. In order to check if the $\mathrm{R}_{8}^{\mathrm{F}}(\mathrm{EO})_{9}-\mathrm{P} 123$ mixtures fit this latter condition, we have performed some dynamic light scattering (DLS) experiments. For a surfactant concentration located at around 1 wt. $\%$, the hydrodynamic diameters of the $\mathrm{R}_{8}^{\mathrm{F}}(\mathrm{EO})_{9}$ and $\mathrm{P} 123$ pure micelles are found to be equal to 7.6 and $18.8 \mathrm{~nm}$, respectively (see supporting information S3). Incorporating $\mathrm{P} 123$ into the $\mathrm{R}_{8}^{\mathrm{F}}(\mathrm{EO})_{9}$ solution, two kinds of micelles are formed up to a 0.3 weight fraction of P123, as depicted Figure 1. The first peak is located at around $8.0 \mathrm{~nm}$, value close to the size of the $\mathrm{R}_{8}^{\mathrm{F}}(\mathrm{EO})_{9}$ micelles, and the second one is located at around $27.0 \mathrm{~nm}$. A further addition of the block copolymer 
leads to only one type of micelles, which diameter is at around $18-19 \mathrm{~nm}$, value close to the size of the P123 micelles. Hence, to prepare the mesoporous materials, the proportion of P123 in the surfactant mixture was kept lower than 0.3.

The SAXS pattern of the mesoporous materials prepared from a $\mathrm{R}_{8}^{\mathrm{F}}(\mathrm{EO})_{9}$ micellar solution at 10 wt. $\%$ exhibits three reflections at $\mathrm{q}$ ratios $1: \sqrt{ } 3: 2$, consistent with a hexagonal symmetry (Fig. 2a). A type IV isotherm is obtained by nitrogen adsorption-desorption analysis and a $\mathrm{HI}$ type hysteresis loop. The pore size distribution is quite narrow and centered at $3.6 \mathrm{~nm}$ (data not shown). It should be noted that under the synthesis conditions reported here, no material is recovered when the synthesis is carried out from a pure micellar solution of P123. As shown in Figure 2, when $\mathrm{P} 123$ is added to $\mathrm{R}_{8}^{\mathrm{F}}(\mathrm{EO})_{9}$, in addition to the reflection lines at 5.3 and 3.1 $\mathrm{nm}$, another peak located at $11.2 \mathrm{~nm}$ is detected (Fig. 2b). Reaching a weight fraction of 0.1 of block copolymer in the mixture, two supplementary lines at 6.4 and $5.6 \mathrm{~nm}$ also appear on the SAXS pattern (Fig. 2c). The relative position of the new peaks is in agreement with a hexagonal mesopore ordering. Thus, the SAXS analysis evidences the presence of two hexagonal channel arrangements. The coexistence of the two structures is further confirmed by the transmission electron microscopy (TEM) images of the sample. Indeed, as depicted in Figure 3, the hexagonal stacking of the two types of channels is evidenced by the TEM analysis. The micrographs show regions of small mesopores and regions of large mesopores. This confirms the results obtained by DLS analysis that two kinds of micelles co-exist in this system. Moreover, looking carefully at Figure 3, the two mesopore networks are connected. Figure 4 shows the nitrogen adsorption-desorption isotherms of the samples prepared with a 0.05 (Fig. 4a) and 0.10 (Fig. 4b) weight fraction of P123 in the surfactant mixture. All compounds exhibit a type IV isotherm of mesoporous materials according to the IUPAC classification $^{32}$. Two distinct capillary condensation steps are clearly seen at $\mathrm{p} / \mathrm{p}_{0}$ values of about 0.50 and 0.75 (Fig. 4A), respectively. The desorption branch also displays two distinct 
steps. This suggests the presence of two pore systems with different diameters are present arranged in a three-dimensional pore structure ${ }^{15}$. BJH model analysis of these materials provides two narrow peaks centered at $3.6 \mathrm{~nm}$ and $9.4 \mathrm{~nm}$ in the pore size (Fig. 4B). With the increase of the P123 content in the surfactant mixture the component at $9.4 \mathrm{~nm}$ increases while the one at $3.6 \mathrm{~nm}$ decreases. However, no significant variation of both mesopore sizes is detected. This phenomenon suggests that the size of each type of micelles remains slightly unchanged, which is in agreement with the results obtained by DLS analysis.

The increase of $\mathrm{P} 123$ proportion in the surfactant mixture over 0.1 induces the progressive disappearance of the smaller mesopores. As a matter of fact, on the SAXS pattern, the reflections at 5.3 and $3.1 \mathrm{~nm}$; associated to the smaller mesopores are not detected anymore (Fig. 2d,e). Moreover, the secondary reflections, characteristic of the bigger mesopores arrangement become less resolved, meaning that its disorganization has begun. This phenomenon can also be noticed from the nitrogen adsorption-desorption analysis (Fig. 5). Indeed, the inflection point at $\mathrm{p} / \mathrm{p}_{0}=0.5$ disappears as well as the component of the pore size distribution related to the smaller pore diameters. At the same time, the second distribution becomes broader (Fig. 5Ba,b).

The investigation of the $\mathrm{R}_{8}^{\mathrm{F}}(\mathrm{EO})_{9} / \mathrm{P} 123 /$ water phase diagram evidences that in the considered surfactant range of concentrations, the system is micellar $\left(\mathrm{L}_{1}\right)$. DLS measurements indicate that this micellar phase is composed of two types of micelles, the size of the first one at around $8.0 \mathrm{~nm}$ corresponds unambiguously to the $\mathrm{R}_{8}{ }_{8}(\mathrm{EO})_{9}$ micelles. Since under the synthesis conditions considered in this work, a micellar solution of P123 does not lead to the formation of any mesoporous material, we can conclude that the second type of micelles consists of $\mathrm{R}_{8}^{\mathrm{F}}(\mathrm{EO})_{9}$ micelles that have accommodated a weak fraction of P123 molecules. It should be noted that to obtain ordered mesoporous materials from a pure P123 micellar solution, the synthesis conditions have to be modified ${ }^{33}$. The proportion between the two 
kinds of micelles depends on the ratio between the two surfactants. For a P123 weight fraction lower than 0.15 , when the silica source is added to the surfactant solution having a total concentration equal to $10 \mathrm{wt} . \%$, hydrogen-bonding interactions between the oxygen atoms of the oxyethylene groups of the two micelles types and hydrogen atoms of the hydrolyzed TMOS are formed. These interactions lead to the formation of two organic-inorganic mesophases. During the material preparation, the silica source polymerizes both around the two kinds of micelles. Finally, the hydrothermal treatment at $80{ }^{\circ} \mathrm{C}$ completes the assembly and the polymerization of the silica source. After surfactant removal, bimodal mesoporous materials having two ordered mesopore networks are obtained. The first one arises from the fluorinated micelles and the mesopore size is around $3.6 \mathrm{~nm}$. The second, which is responsible of the pore size distribution centered at $9.4 \mathrm{~nm}$, comes from the fluorinated micelles that have accommodated the P123 molecules. The scheme proposed in Figure 6 illustrates the formation of these bimodal ordered mesoporous materials.

If the triblock copolymer loading is increased over 0.15 , more and more P123 molecules are accommodated by the fluorinated micelles and the number of the pure $\mathrm{R}_{8}^{\mathrm{F}}(\mathrm{EO})_{9}$ micelles decreases. The SAXS and nitrogen adsorption-desorption analysis reveal that the smaller mesopores disappear. Only the larger one is maintained. The system evolves towards the formation of mono-sized mixed micelles. This tendency is supported by the DLS experiments, which evidence the formation of one type of micelles having a hydrodynamic diameter close to the one of the pure P123 micelles when the P123 fraction in the surfactant mixture reaches 0.3 (Fig. 1). P123 molecules govern the micelles and the mesopore ordering is progressively lost as observed when the pure P123 micellar solution is used to prepare the materials under the synthesis conditions reported here. 


\section{Conclusion}

Bimodal mesoporous silica with two hexagonal ordered mesopore networks have been synthesized through the self assembly mechanism from a micellar solution of fluorinated and triblock copolymer surfactants, which contains two types of micelles. DLS measurements indicate that the proportion between the two kinds of micelles depends on the ratio between the two surfactants. It should also be noted that both the fluorinated and the P123 surfactants, when used separately only lead to the formation of mono-modal mesoporous materials. Thus, the results reported here clearly show that the bimodality is due to the template.

As long as the two networks are present, no significant variation of both mesopore sizes is detected with the variation of the P123 content in the surfactant mixture.

\section{Supporting informations available:}

Mid infrared spectrum of a mesoporous silica material prepared by using the fluorinated surfactant (S1). Water rich part of the $\mathrm{R}_{8}^{\mathrm{F}}(\mathrm{EO})_{9} / \mathrm{P} 123 /$ water phase diagram (S2). Hydrodynamic diameter of the $\mathrm{R}_{8}^{\mathrm{F}}(\mathrm{EO})_{9}(\mathrm{~A})$ and $\mathrm{P} 123$ (B) micelles (S3).

\section{ACKNOWLEDGEMENTS :}

Authors would like to thank DuPont de Nemours Belgium for providing the fluorinated surfactant. Anna May would like to thank the Spanish MICINN for the financial support within the framework of the project number CTQ2008-06892-C03-03/PPQ. 


\section{References}

1 Cundy, C.S. and Cox, P.A. Chem. Rev., 2003, 103, 702.

2 Hentze, H.P. and Antonietti, M. Curr. Opin. Solid. St. M., 2001, 5, 343.

3 Schüth, F. Angew. Chem. Int. Ed., 2003, 42, 3604.

4 Holland, B.T.; Blanford, C.F.; Do, T. and Stein, A. Chem. Mater.,1999, 11, 795.

5 Wackeman, R.J.; Bhumgara, Z.G. and Akay, G. Chem. Eng. J., 1998, 70, 133.

6 Keshavaraja, A.; Ramaswamy, V.; Soni, H.S.; Ramaswamy, A.V. and Ratnasamy, P. J. Catal., 1995, 157, 501.

7 Holland, B.T.; Abrams, L. and Stein, A. J. Am. Chem. Soc., 1999, 121, 4308.

8 Blin, J.L.; Léonard, A.; Yuan, Z.Y.; Gigot, L.; Vantomme, A.; Cheetham, A.K. and Su, B.L. Angew. Chem., Int. Ed., 2003, 42, 1644.

9 Blanford, C.F.; Yan, H.; Schroden, R.C.; Al-Daous, M. and Stein, A. Adv. Mater., 2001, 13, 401.

10 Sen, T.; Tiddy, G.J.T.; Casci, J.L. and Anderson, M.W. Chem. Commun., 2003, 17, 2182.

11 Nakanishi, K., Kobayashi, Y., Amatani, T.; Hirato K. and Kodaira, T. Chem. Mater., 2004, 16, 3652 .

12 Blin, J.L.; Bleta, R.; Ghanbaja, J. and Stébé, M.J. Microporous and Mesoporous Mater., 2006, 94, 74 .

13 Morri, H.; Uota, M.; Fujikawa, D.; Yoshimura, T.; Kuwahara, T.; Sakai, G. and Kijima, T. Microporous and Mesoporous Mater., 2006, 91, 172.

14 Sel, O.; Kuang, D.; Thommes, M. and Smarsly, B. Langmuir, 2006, 22, 2311.

15 Bagshaw, S.A. Chem. Commun., 1999, 18, 1785.

16 J. H. Sun, Z. Shan, T. Maschmeyer and M.O. Coppens, Langmuir, 2003, 19, 8395.

17 Yuan, Z.Y.; Blin, J.L. and Su, B.L. Chem. Commun., 2002, 5, 504. 
18 Groenewolt, M.; Antonietti, M. and Polarz, S. Langmuir, 2004, 20, 7811.

19 Xing, R.; Lehmler, H.J.; Knutson, B. and Rankin, S.E. Langmuir, 2009, 25, 6486.

20 Wang, W.; Dou, T. and Xiao, Y. Chem. Commun., 1998, 9, 1035.

21 Chen, L.; Xu,J.; Zhang, W.H.; Holmes, J.D. and Morris, M.A. J. Colloid and Interface Sci., 2011, 353, 169.

22 Chen, L.; Zhang, W.H.; Xu, J.; Tanner, D.A. and Morris, M.A. Microporous and Mesoporous Mater., 2010, 129, 179.

23 Blin, J.L.; Henzel, N. and Stébé, M.J. J.Colloid and Interface Sci., 2006, 302, 643.

24 Michaux, F.; Blin, J. L. and Stébé, M. J. Langmuir, 2007, 23, 2138.

25 Almgren, M. and Wang, K. Langmuir, 1997, 13,4535.

26 M. Kadi, P. Hansson and M. Almgren, Langmuir, 2004, 20, 3933.

27 Ravey, J.C.; Gherbi, A. and Stébé, M.J. Prog. Colloid polymer. Sci., 1989, 79, 272.

28 Amato, M.E.; Caponetti, E.; Martino, D.C. and Pedone, L. J. Phys. Chem. B, 2003, $107,10048$.

29 Blin, J.L.; Lesieur, P. and Stébé, M.J. Langmuir., 2004, 20, 491.

30 Michaux, F.; Stébé, M.J. and Blin, J.L. Microporous and Mesoporous Mater., 2011, 10.1016/j.micromeso.2011.10.035.

31 Barret, E.P.; Joyner, L.G. and Halenda, P.P. J. Am. Chem. Soc., 1951, 73, 37.

32 Sing, K.S.W.; Everett, D.H.; Haul, R.A.W.; Moscou, L.; Pierotti, R.A.; Rouquerol, J. and Siemieniewska, T. IUPAC, Pure and Appl. Chem., 1985, 57, 603.

33 Li, J.; Hu, Q.; Tian, H.; Ma, C.; Li, L.; Cheng, J.; Hao, Z. and Qiao, S. Colloid and Interface Sci., 2009, 339, 160. 


\section{Figure captions}

Figure 1: Evolution of the hydrodynamic diameters as a function of the P123 content in the surfactant mixture.

Figure 2: SAXS patterns of samples synthesized from the surfactants mixture with a : 0 , b : $0.05, c: 0.10, d: 0.15$ and e $: 0.20$ weight fraction of P123.

Figure 3: Representative TEM micrographs of sample prepared with a 0.10 weight fraction of P123 in the surfactants mixture.

Figure 4: Nitrogen adsorption-desorption isotherm (A) and pore size distribution (B) of the mesoporous materials prepared with a 0.05 (a) and 0.10 (b) weight fraction of P123 in the surfactant mixture.

Figure 5: Nitrogen adsorption-desorption isotherms (A) and pore size distribution (B) of the recovered silica prepared with a 0.15 (a) and 0.20 (b) weight fraction of P123 in the surfactant mixture.

Figure 6: Scheme illustrating the formation of the bimodal mesoporous materials having two ordered mesopore networks. 


\section{Figure 1}

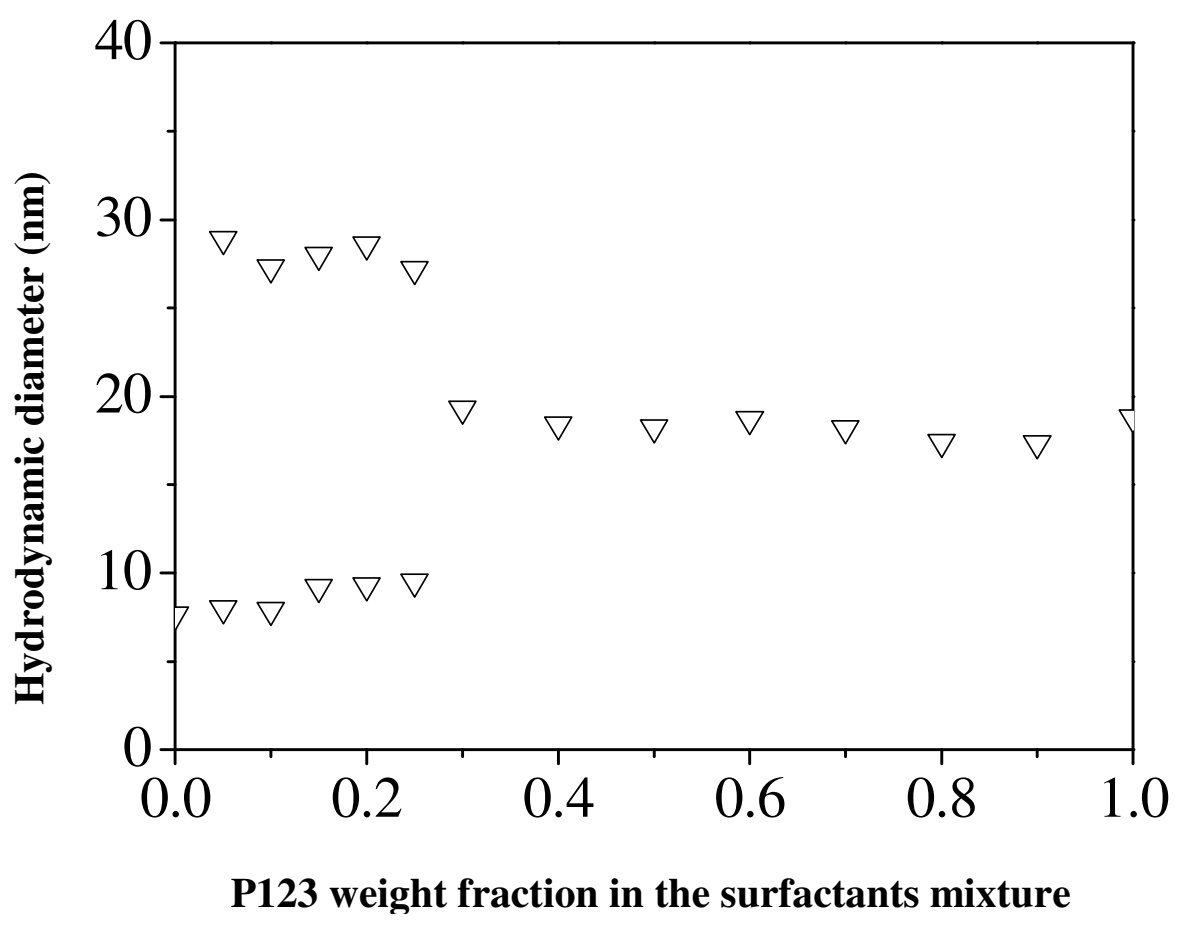


Figure 2

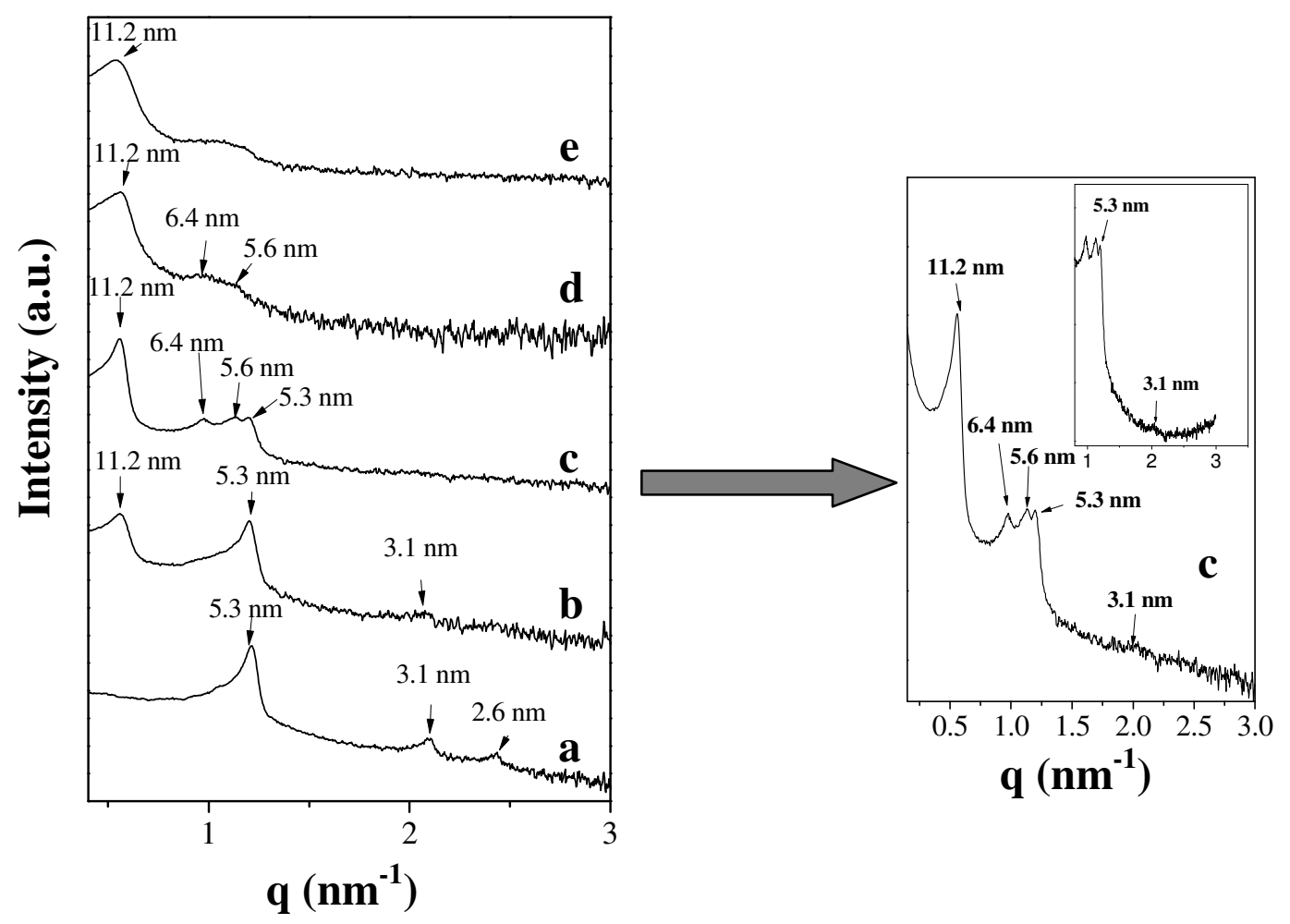




\section{Figure 3}
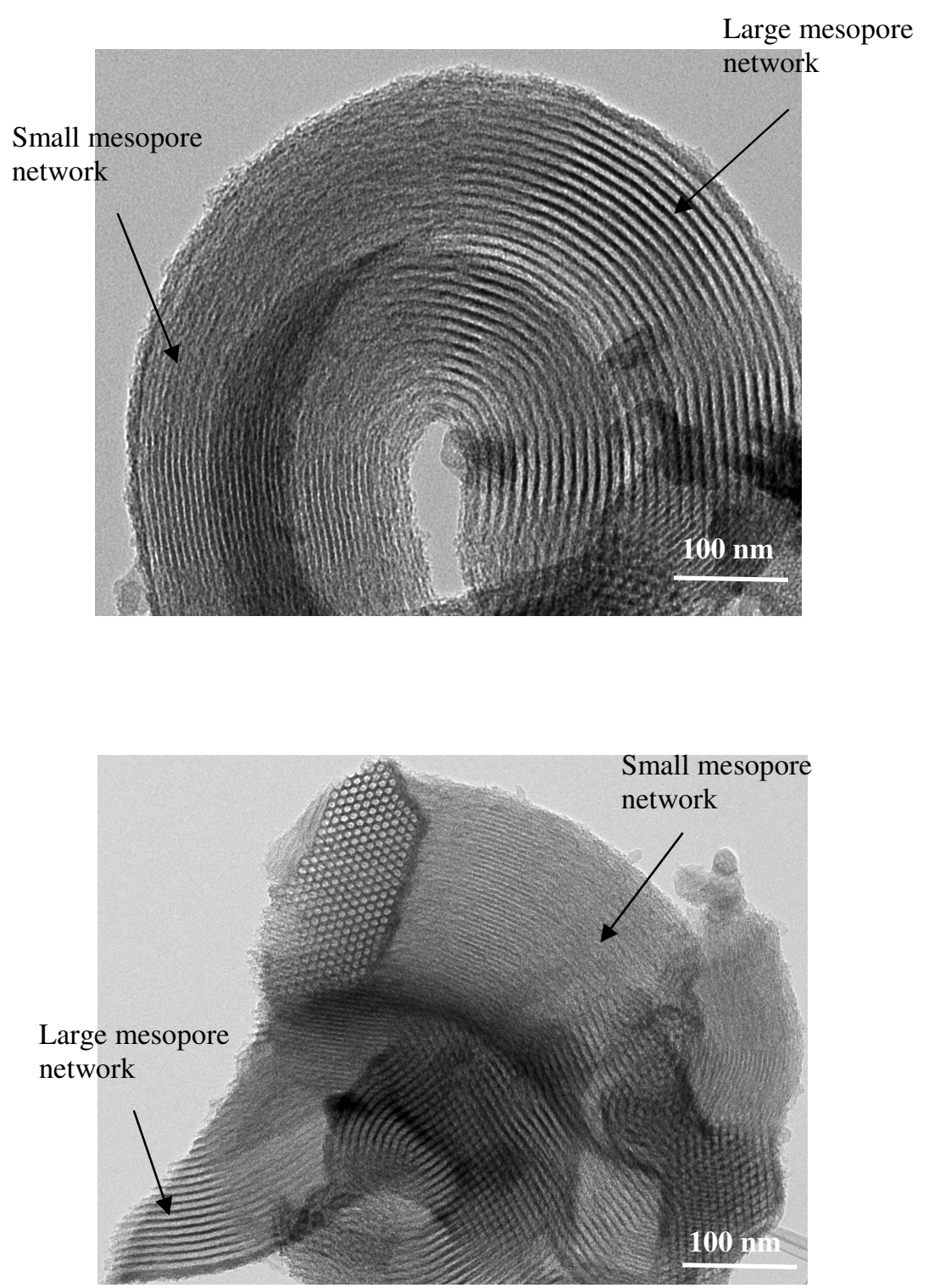


\section{Figure 4}

A
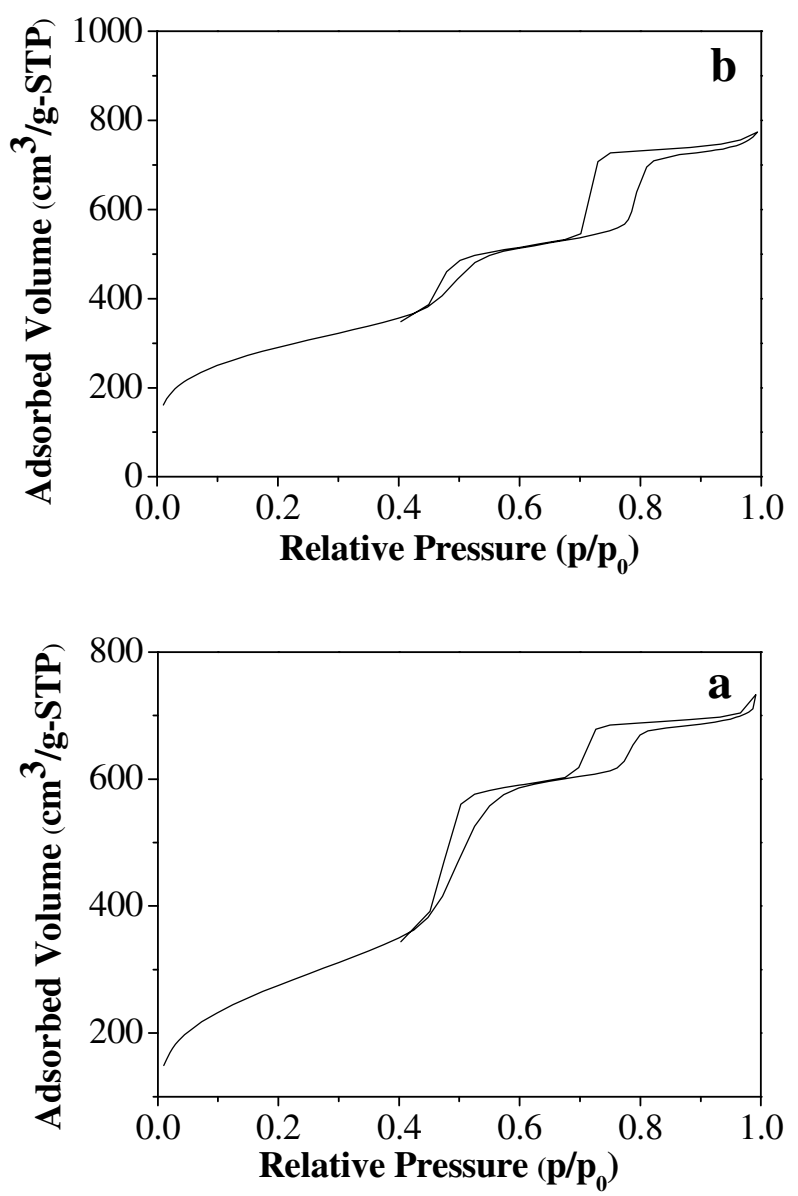

B
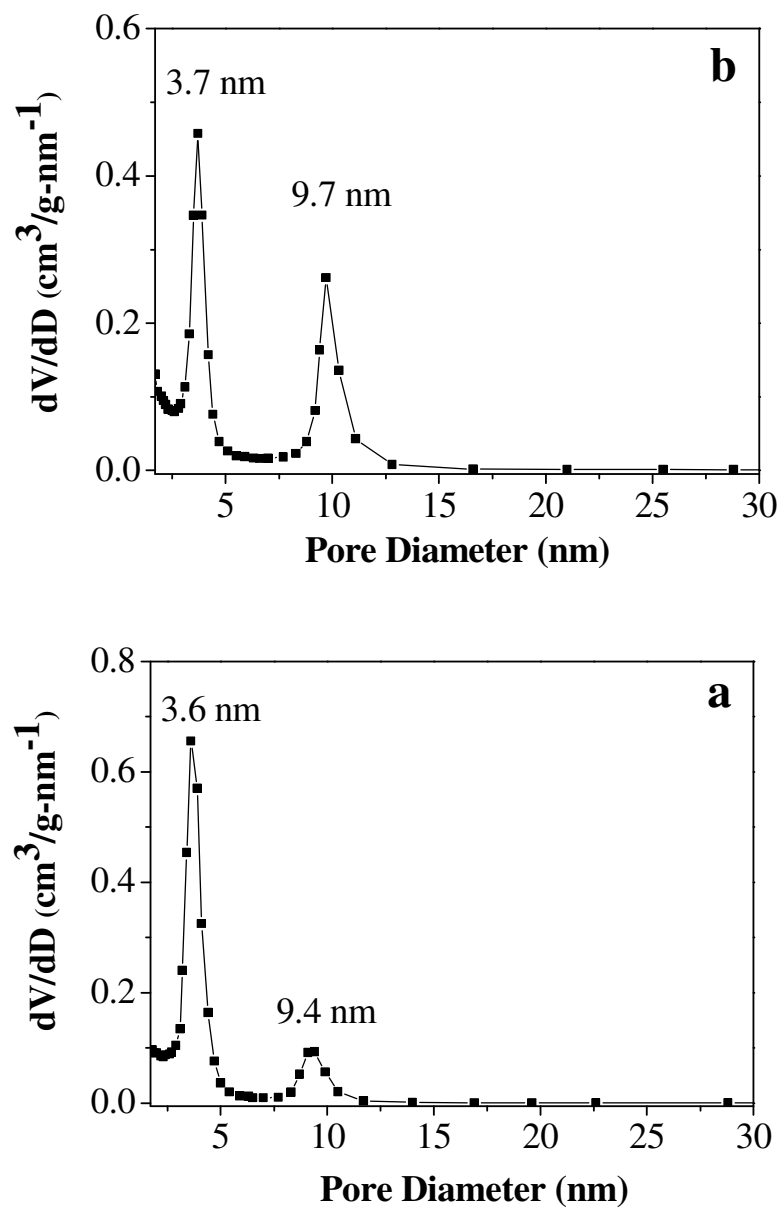


\section{Figure 5}

A
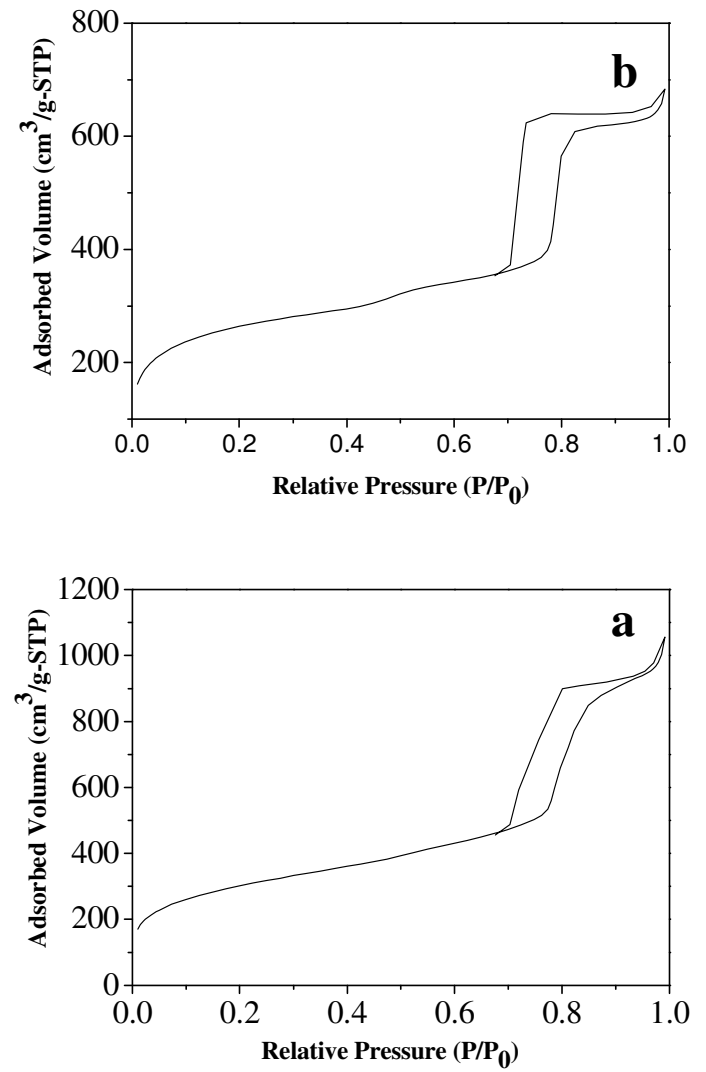

B
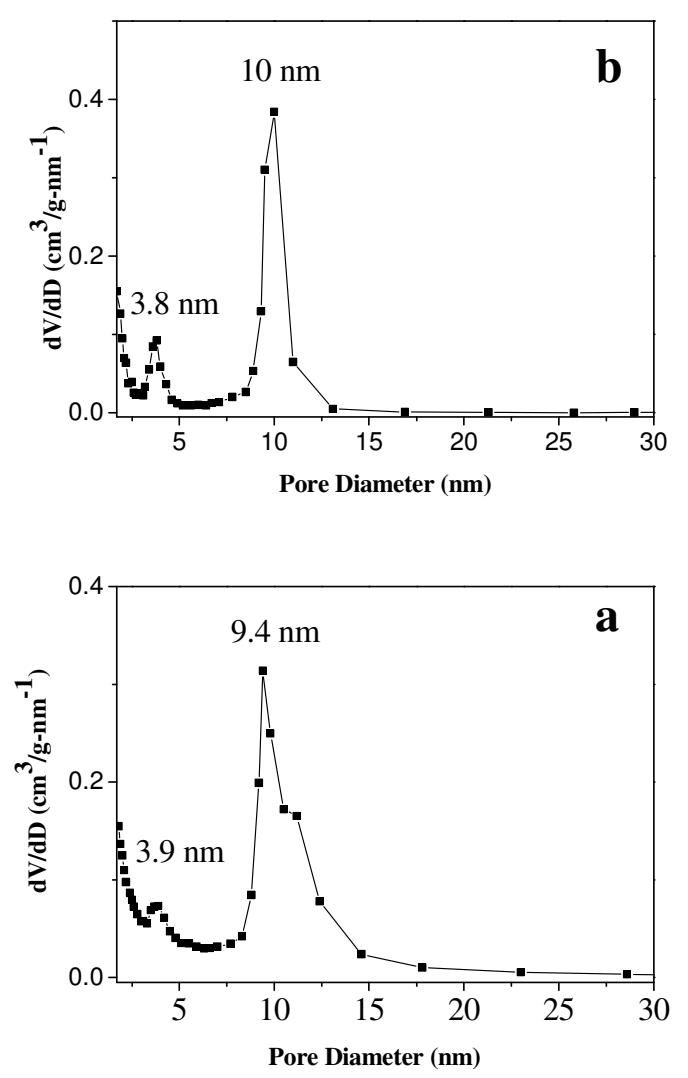
Figure 6

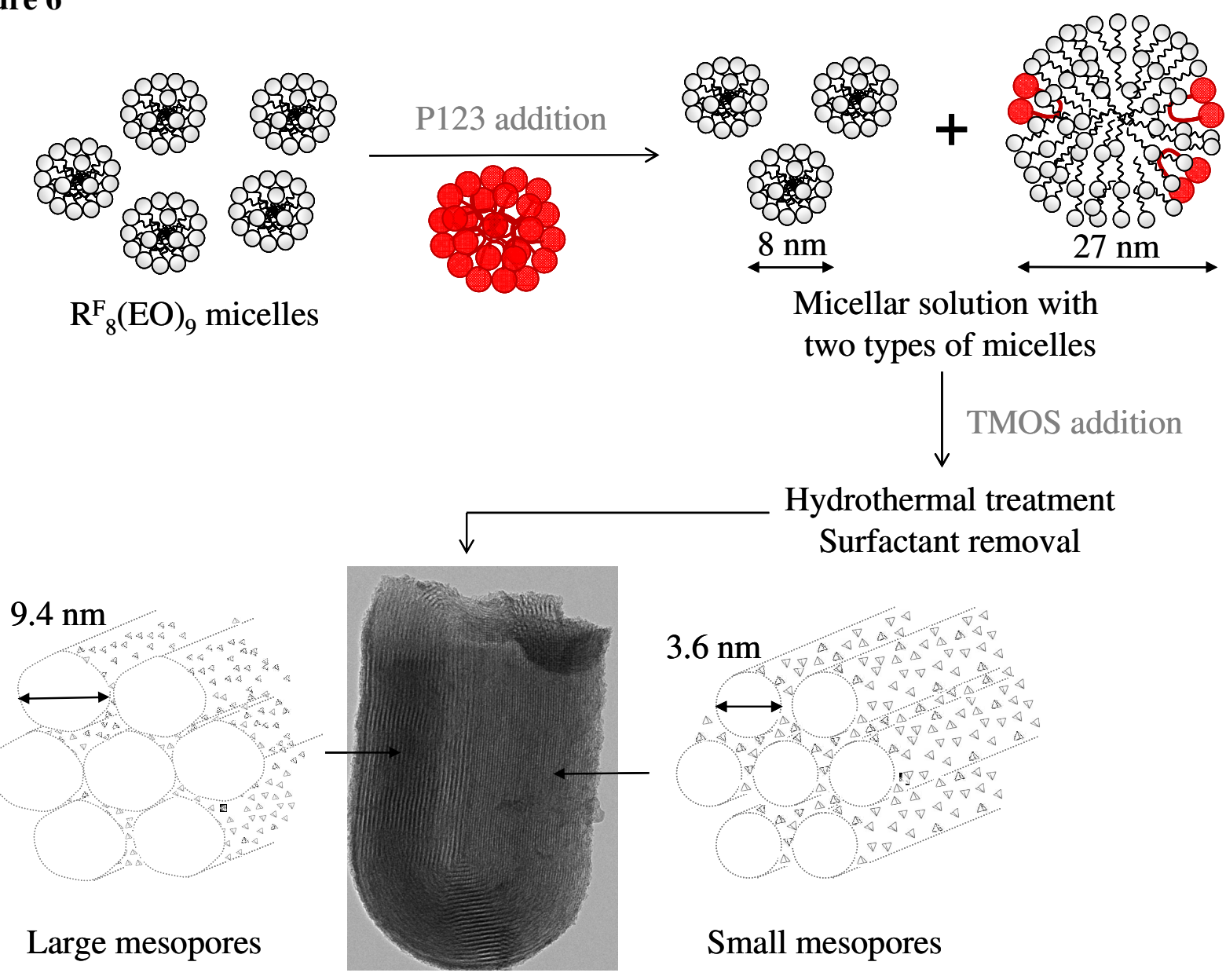




\section{Page 19 of 19}

TOC

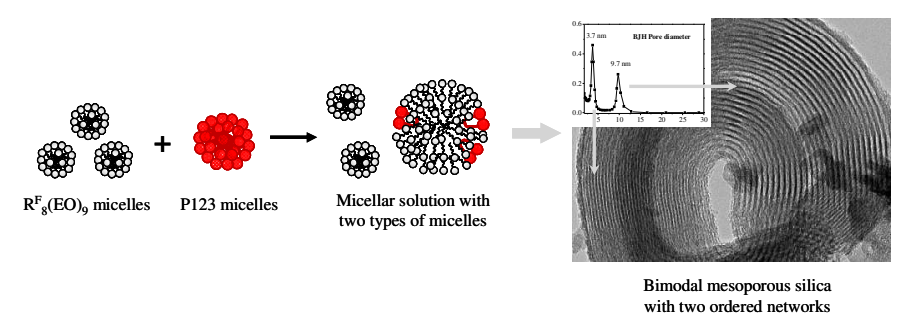

1

3

4

5

6
7

8

9

10

11

12

13

14

15

16

17

18

19

20

21

22

23

24

25

26

27

28

29

30

31

32

33

34

35

36

37

38

39

40

41

42

43

44

45

46

47

48

49

50

51

52

53

54

55

56

57

58

59 